\title{
Polish Society of Gynecologists and Obstetricians recommendations on supplementation during pregnancy
}

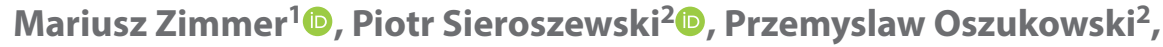 \\ Hubert Huras $^{3}{ }^{(D}$, Tomasz Fuchs ${ }^{1}{ }^{10}$, Agata Pawlosek ${ }^{1}$ \\ ${ }^{1} 2^{\text {nd }}$ Department of Gynecology and Obstetrics, Wroclaw Medical University, Wroclaw, Poland \\ ${ }^{2}$ Department of Obstetrics and Gynecology, Medical University of Lodz, Poland \\ 3 Jagiellonian Univeristy Collegium Medicum, Department of Obstertics and Perinatology, Cracow, Poland
}

\begin{abstract}
The recommendations present the current state of knowledge on the presented subject on the day of publication.
\end{abstract}
The board of experts reserves the right to update the information in case of new significant scientific reports.

The board of experts undertook the analysis of literature, expert knowledge and clinical experience in matters of use of dietary supplementation in pregnancy.

\section{INTRODUCTION}

Progress in medicine allows for a better understanding of the purpose of dietary components in prophylaxis of civilization diseases and suggests that alimentation not only supplies energy and nutrients but provides compounds essential for proper functioning of the body as well [1].

Based on every day medical practice we can conclude that future mothers attach relatively substantial importance to their diet. They realize the importance of diet and its impact on the condition and development of the fetus. It is common among pregnant women to use dietary supplements, which often does not have any rational justification.

It is estimated that about 78-98\% of pregnant women in the USA, Canada and Australia use dietary supplements [2]. There are no reliable data from Poland, but observations in obstetrical practice let us assume that the supplementation trend is very similar.

In literature there are contradictory reports regarding the safety and effectiveness of supplementation usage by pregnant women.

According to the WHO statement from 2016, as well as the majority of medical associations, a routine usage of multivitamin regimens by all pregnant women is not recommended. The basic source of microelements and vitamins should come from a well-balanced diet.

The following recommendations of the Polish Society of Gynecologists and Obstetricians present an up-to-date view on the importance of dietary supplementation in pregnancy in accordance with current knowledge and recommendations. We present five active substances - iron, folic acid, vitamin D, DHA acid and iodine, which are considered to be the basic elements useful in pregnancy supplementation. Presence of other microelements, vitamins and active substances in supplementation, therefore supplementing a normal diet is not recommended in a population of healthy women with no specified medical indications.

\section{IRON}

We talk about iron balance as a resultant of two factors: iron intake and loss. The total amount of this element in adults is about $4-5 \mathrm{~g}$ and is mostly present as a component of hemoglobin (75\%), ferritin and hemosiderin (20\%). In proper conditions there is a state of dynamic balance between the iron contained in hemoglobin and the storage and transport proteins.

Outside of pregnancy, a regular diet usually fully covers the daily requirement for iron. It increases during pregnancy daily by about $1 \mathrm{mg}$ in the first trimester and $7.5 \mathrm{mg}$ in the third trimester, which is the result of an increasing demand of a growing fetus, placenta and an increasing volume of the uterine muscle [3]. Iron deficiency is the most common cause of anemia in pregnancy.

The lower limit of hemoglobin in pregnancy defined by $\mathrm{WHO}$ is $11 \mathrm{~g} / \mathrm{dL}$ (6.8 $\mathrm{mmol} / \mathrm{L})$. Anemia in pregnancy is defined by the level of $\mathrm{Hgb}$ below $11 \mathrm{~g} / \mathrm{dL}$ in every trimester of pregnancy according to WHO [4]. Undoubtedly, it is quite a big interpretive simplification, though one giving the possibility of applying unified and proper treatment. When analyzing the necessity of iron supplementation, it is more useful to divide the normal range for hemoglobin depending on the 
trimester of pregnancy. CDC runs a simplified scheme of such range considering Hgb concentration $<11 \mathrm{~g} / \mathrm{dL}$ in I and III trimester and $\mathrm{Hgb}<10.5 \mathrm{~g} / \mathrm{dL}$ in II trimester as reference ranges for diagnosing anemia in pregnancy $[2,5-7]$.

In "The Global Prevalence of Anemia in 2011" report, WHO states that in Europe anemia occurs in about 20-40\% of all pregnant women aged 15-49, and it simultaneously recommends iron supplementation of all pregnant and planning pregnancy women, 30-60 mg daily to reduce the risk of perinatal complications, infections, low birth weight and preterm births.

The majority of scientific societies (Royal College of Obstetrics and Gynaecology (RCOG), Royal Australian and New Zealand College of Obstetrics and Gynaecology (RANZCOG), European Food Safety Authority (EFSA), Scientific Advisory Committee on Nutrition (SACN), British Society for Haematology, Obstetric Haematology group (BSH OHG) and British Committee for Standards in Haematology (BSCH) do not share this position, recommending iron supplementation only in case of deficiency.

The Polish Society of Gynecologists and Obstetricians shares this view. These recommendations result from the fact that, in recent years, it has been observed that there is a potential adverse effect of iron excess on the course of pregnancy and obstetric outcome. Iron takes part in the formation of reactive forms of oxygen and is responsible for development of insulin resistance and reduced insulin secretion by the pancreatic beta cells [11, 12]. Current research indicates a possible link between iron excess and risk of preeclampsia, especially among women supplementing iron before 16 weeks of gestation with normal $\mathrm{Hgb}$ concentration $(\mathrm{Hgb}>13.2 \mathrm{~g} / \mathrm{dL}$ at the beginning of the second trimester) [13-15].

In numerous studies, including two large meta-analyses, a correlation has been shown between the incidence of type two and gestational diabetes and the amount of iron stored in the body measured by iron concentration, hemoglobin and ferritin in blood serum [16-19].

Moreover, gestational diabetes has been shown to be more frequent in women supplementing iron that have normal hemoglobin levels $[19,20]$. Helin et al. [21], showed that the occurrence of gestational diabetes was more frequent in a group of women with $\mathrm{Hgb}>12 \mathrm{mg} / \mathrm{dL}$ with an average of $14.4 \mathrm{mg}$ of iron in diet and an average of $27 \mathrm{mg}$ in the form of Fe2+ supplements during preconception and in the first trimester.

The total iron requirement in pregnancy is about $1-1.2 \mathrm{~g}$, of which approx. 500-600 mg participate in the development of pregnancy and the rest is the basic requirement of the body.

According to literature reports, it can be concluded that women with iron supplies of about $500 \mathrm{mg}$, which cor- responds to ferritin concentration of about $60-70 \mathrm{mcg} / \mathrm{L}$, most likely will not develop anemia nor iron deficiency in pregnancy, despite the lack of supplementation [3].

Complete iron depletion from the reserve iron storage is evidenced by ferritin concentration $<12 \mathrm{mcg} / \mathrm{L}$ [5].

With ferritin level $<60 \mathrm{mcg} / \mathrm{L}$ in women without anemia, oral iron supplementation can be considered in small doses up to about $30 \mathrm{mg}$ daily after 16 weeks of gestation, for a longer period of time, which is related to the availability of storage and transport proteins [22].

It is also important to be aware of other possible, anemia causes during pregnancy, like chronic diseases, infectios, B12 vitamin deficiency or malignant tumors.

Considering the above, an insightful analysis of the mean corpuscular volume of erythrocytes (MCV) and ferritin concentration is recommended (Fig. 1), according to the diagram below. It allows appropriate implementation of dietary supplement with or without low dose iron (up to $30 \mathrm{mg}$ ) (Fig. 1).

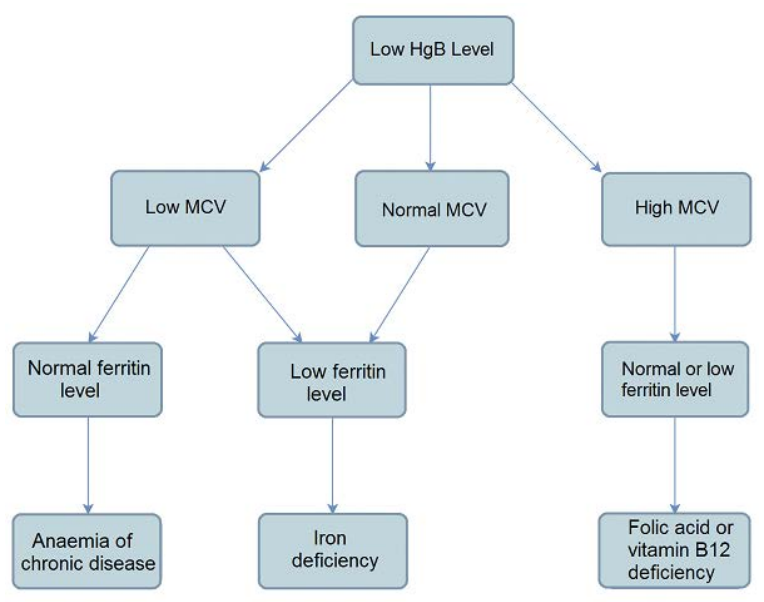

Figure 1. Management of anemia in pregnancy

The blood count test is a basic element of standard prenatal care. Its assessment should not only be based on the analysis of hemoglobin or hematocrit levels, but also MCV levels, which is an inherent parameter of the result. During anemia diagnostic tests it is recommended to examine the level of ferritin, which determines the necessity of introducing therapeutic doses of iron.

\section{Summary}

Taking into consideration the negative impact of both iron deficiency and excess on the course of pregnancy, obstetric results and possible causes of anemia in pregnancy other than iron deficiency, it is recommended to:

1. Assess blood count and ferritin concentration at the first prenatal visit and then the blood count at 15-20, 27-32, 
33-37 and 38-39 weeks of gestation (in accordance with the Standard Management of Physiological Pregnancy - a regulation of the Polish Minister of Health),

2. Use iron regimens before 16 weeks of gestation in women with iron deficiency anemia (with $\mathrm{Hgb}<11 \mathrm{~g} / \mathrm{dL}$ and low ferritin level),

3. Allow iron supplementation up to $30 \mathrm{mg}$ daily in women without anemia with ferritin level below $60 \mathrm{mcg} / \mathrm{L}$ after 16 weeks of gestation,

4. Use low oral doses of iron for longer period of time as treatment of iron deficiency anemia, and in the absence of improvement change to a preparation of higher proven availability or increase the dose and further observe the Fe levels,

5. Analyze the necessity of packed red cells transfusion in case of no response to high therapeutic doses of oral iron or $\mathrm{Hgb}<7 \mathrm{~g} / \mathrm{dL}$.

\section{DOCOSAHEXAENOIC ACID (DHA)}

Concentration of lipids (fats) in the human central nervous system is about $60 \%$ of its dry mass, which puts it in the second place of lipid concentration in human body, right after the adipose tissue.

Lipids are the structural core (building material) of all biological membranes surrounding cells of living organisms, which have a major impact on the structure of membranes, their fluidity and elasticity.

Scietific studies show that high DHA concentration in membrane phospholipids affects the function, survivability and plasticity of neurons, and its deficiency or slow metabolism is certainly one of the causing factors of cognitive function decline, developing mental illnesses or neurodegenerative diseases [23] and is important for neuron protection against apoptosis induced by oxidative stress [24].

All these characteristics of membranes increase their "dynamics" in comparison with membranes built from phospholipids with a different building material [23].

An adequate DHA amount during pregnancy and lactation is therefore essential for preserving the proper development at cellular and neural level, and in consequence ensuring proper visual acuity and normal psychomotor development of the child. It also reduces the risk of depression incidence in the mother [3,22].

Fetal DHA requirement is significantly increased in the third trimester of pregnancy. In published research, including meta-analyses, it was shown that omega-3 fatty acids supplementation reduces the risk of preeclampsia [25] and preterm birth [26-28].

In 2018 Olsen showed a 10-times higher risk of preterm birth before the 34 weeks of gestation in a group of women whose percentage of eicosapentaenoic acid (EPA) and DHA in the fatty acid pool was $<1.6 \%$ in comparison with women whose EPA and DHA percentage $\geq 1.8 \%(95 \% \mathrm{Cl} 6.80-15.79$, $\mathrm{p}<0.0001$ ) [29].

Currently there are insufficient data to define target levels of DHA in blood serum, however the red blood cell (RBC) DHA level < $5 \%$ seems to have an effect of increasing the risk of preterm birth $[29,30]$.

The effect of omega-3 fatty acids on the reduction of the preterm birth risk is most likely the result of their anti-inflammatory properties.

One of the mechanisms for developing uterus contractions is the increase of connexin 43 and activation of myometrial receptors for oxytocin and prostaglandins. DHA stabilizes cell membranes by, i.e. modulation of Connexin 43 expression.

EPA competes with arachidonic acid (ARA), which is a source of $E 2$ and $F 2$ alpha prostaglandins.

The connection between consumption of fish and duration of pregnancy has been observed for many years, there are, however discrepancies in the recommended dose of polyunsaturated fatty acids.

Academy of Nutrition and Dietetics recommends supplementation of $500 \mathrm{mg}$ of DHA daily for women that consume little amounts of fish, which is an equivalent of 2 portions of wild pacific salmon.

World Association of Perinatal Medicine recommends supplementation of at least $200 \mathrm{mg}$ daily for all pregnant women [30].

Fish, algae and other seafood are a natural source of DHA, but one should keep in mind that fish can also be a source of environmental pollutants such as mercury, dioxins or polichlorinated biphenyls (PCBs). The highest levels of mercury are found in fish at the top of the food chain, such as shark, swordfish or tuna [31].

It seems justified that women at risk of DHEA deficiency, i.e. consuming low (lower than mentioned above) amount of fish, both during pregnancy and in the preconception period, should use polyunsaturated fatty acids in the form of supplements.

It is not entirely clear if increasing the DHA dose up to $600-1,000 \mathrm{mg}$ daily brings benefits the further decline of the percentage of premature and very premature deliveries ( $<34$ weeks of gestation), but it is known that DHA supplementation in doses up to $2,100 \mathrm{mg}$ per day is not associated with any side effects neither for the pregnant woman nor the fetus) [30].

The DOMInO study involving 2,399 women in singleton pregnancies has shown that the incidence of very premature deliveries ( $<34$ weeks of gestation) was higher in a group of women using placebo in comparison to women consuming $800 \mathrm{mg}$ of DHA + 100mg of EPA per day $(p=0.03)$ [32].

In a multicenter Australian ORP study published in 2019, comprising of 5,486 women in singleton and multiple preg- 
nancies, taking not more than $150 \mathrm{mg}$ of DHA daily, a relevant statistical difference was not found in the incidence of very premature deliveries between women taking $900 \mathrm{mg}$ of DHA per day additionally and a group of women also using vegetable oil containing only small amounts of DHA [33].

Currently the ADORE study is conducted in a group of 900-1,200 women and aims to compare the incidence of very premature deliveries in groups of pregnant women supplementing 200 and $1,000 \mathrm{mg}$ of DHA per day. The study is expected to be completed in 2021[34].

Perhaps it will allow for determining the optimal dose of DHA supplementation in pregnancy.

\section{Summary}

Considering all available knowledge about DHA impact on the course of pregnancy and obstetric outcomes, it is currently recommended to:

1. Supplement at least $200 \mathrm{mg}$ of DHA in all pregnant women,

2. Consider using higher doses of DHA in women consuming small amounts of fish during pregnancy and in the preconception period,

3. Use $1,000 \mathrm{mg}$ of DHA daily in the group of women at risk of premature birth.

\section{VITAMIN D}

Vitamin $D$ is a group of fat-soluble steroidal organic compounds. Two forms of vitamin D differing in the structure of the side chain are the most relevant ones: vitamin D2 (ergocalciferol) supplied to the human body with yeast and plant food and vitamin D3 (cholecalciferol) supplied with food of animal origin and produced in the skin under the influence of UV radiation [35].

Both D2 and D3 vitamins have no biological activity. It is only obtained through hydroxylation, which results in the formation of 1a, 25-dihydroxyvitamin D. The activation process takes place successively in the liver and then the kidneys, where both active forms of vitamin D2 and D3 [1 a, 25-(OH) 2D2 and 1a, 25-(OH) 2D3] of identical biological properties are ultimately formed [36].

The role of vitamin $D$ in regulating calcium and phosphorus levels in blood serum, maintaining the correct bone mineral density and its modulating effect on the function of the immune system has been commonly known. It cannot be ruled out that vitamin $D$ deficiency may also play a role in the incidence of recurrent miscarriages, especially those of unspecified etiology [2].

Most randomized controlled trials have shown a positive effect of vitamin D on the course of pregnancy, however only when supplementation was started during placentation [37]. A precise effect of vitamin D on the process of placentation has not yet been explained.
It is known that $1.25(\mathrm{OH}) 2 \mathrm{D}$ affects the HOXA10 gene expression, responsible for uterine development in fetal life, development of endometrium, implantation and the trophoblast invasion into decidua [38].

A meta-analysis of 22 studies (consisting of 3,725 women in total) has indicated, that vitamin D supplementation in pregnancy in comparison with placebo, probably reduces the risk of preeclampsia [risk ratio (RR) $0.48,95 \%$ confidence interval (Cl) $0.30-0.79 ; 4$ studies, 499 women], gestational diabetes (RR $0.51,95 \% \mathrm{Cl} 0.27-0.97 ; 4$ studies, 446 women) and LBW $(<2,500 \mathrm{~g})$ (RR 0.55, 95\% Cl 0.35-0.87; 5 studies, 697 women).

It is likely that vitamin D supplementation also reduces the risk of postpartum hemorrhage (RR $0.86 \%, 95 \% \mathrm{Cl} 0.51-$ -0.91 ; 1 study, 1,134 women) [39]. Another meta-analysis comprising of 16 studies, 28,285 women in total, has shown a relationship between vitamin $D$ deficiency in pregnancy and the incidence of SGA [40].

However, it should be emphasized that some of the quoted studies were not randomized.

The most relevant source of vitamin D for the human body is its synthesis through the skin. In Poland it is possible only from March to September and requires an exposure lasting at least half an hour without the use of sunscreen with UV filters [22]. Polish data, however, indicate a significant vitamin $D$ deficiency in newborns regardless of the season when they were born [41].

In studies conducted in a group of pregnant women from the USA, Northern Europe and the Middle East it has been shown that 26-90\% of them have vitamin D deficiency, defined as $1.25(\mathrm{OH}) 2 \mathrm{D}$ concentration $<50 \mathrm{mmol} / \mathrm{L}$ [2]. Women with $\mathrm{BMI}>30$ are at particularly high risk of vitamin D deficiency. It is believed that their diet does not contain or contains not enough vitamin D. In most European countries and in the USA, supplementation of at least $600 \mathrm{IU}$ of vitamin D per day is recommended. It is recognized that a dose of 1,500-2,500 IU in pregnancy and lactation could keep the vitamin D concentration in blood serum $>75 \mathrm{nmol} / \mathrm{L}$. In most pregnant women it largely depends on their general health condition, individual diet and overall life hygiene. Choosing the correct dose of the supplement would be much easier after performing a blood test determining its actual concentration in the serum. Most often, for practical reasons for the purposes of laboratory diagnostics, the combined concentration of $25-\mathrm{OH}-\mathrm{D} 2$ and 25-OH-D3 is determined [42].

However, these tests go far beyond the standard perinatal care and are sometimes used for clinical trials developing conclusions disseminated later in recommendations.

The studies conducted so far have not shown any adverse effect of vitamin $D$ supplementation in pregnancy up to 4,000 IU per day [37]. Assessment of vitamin D serum con- 
centration in pregnant women would allow for selection of an individual dose which is particularly important in group of women at higher risk of 1.25(OH)2D deficiency, i.e. obese, with liver or kidney disease, chronic intestinal and thyroid gland diseases, or with diabetes, using antiepileptic or antiretroviral drugs [43]. Perhaps it would also allow for variation of the recommended dose in individual deficiency risk groups.

\section{Summary}

According to the current knowledge, it is recommended to:

1. Supplement $1,500-2,000$ IU of vitamin D per day during pregnancy and lactation in women without factors suggesting vitamin D deficiency,

2. Adjust the vitamin $D$ dose in pregnant women to its levels in the blood serum (optimal treatment),

3. Consider doses up to $4000 \mathrm{IU}$ per day in women with high body mass index (BMI) $>30 \mathrm{~kg} / \mathrm{m}^{2}$ [44].

\section{IODINE}

During pregnancy the requirement for iodine increases, which is related to its loss through kidneys, deiodinase activity and fetal demand [22], however, the recommendations for supplementation of this element in pregnancy differ depending on the world region and the level of its deficiency in a given population. Significant iodine deficiency can be a cause of hypothyroidism in both pregnant woman and fetus, disorders of nerve myelination, CNS damage, mental retardation, hearing loss and deafness in newborns, as well as an increased risk of miscarriage and preterm deliveries.

However, such correlation was not observed in cases of mild and moderate deficiency i.e. with UIC (Urinary lodine Concentration) in the range of $50-150 \mathrm{mcg} / \mathrm{L}[45,46]$.

lodine supplementation during the preconception period and in early pregnancy may reduce the risk of mental retardation of a newborn.

Despite the introduction of the WHO-recommended salt iodization programme, Europe still remains a region of iodine deficiency, with only $66 \%$ of children of school age having its adequate level. One should keep in mind that the requirement for iodine in pregnant women is approx. 1.5 times higher. In 2/3 of European countries, including Poland, it has been found that the median iodine level in pregnant women is below the norm, meaning that at least $50 \%$ of pregnant women in Poland suffer from iodine deficiency [47].

The best sources of iodine in diet are dairy products, eggs, fish and iodized salt. For women avoiding dairy products because of intolerance or by choice, or those limiting the intake of salt, providing a sufficient iodine supply without its supplementation is usually difficult to achieve.

It should also be mentioned that one of the elements that relatively easily displaces iodine from the organism is fluorine, commonly added to drinking water in many countries.

Numerous scientific studies directly point out the correlation between excessive consumption of this element and hypothyroidism, therefore an increased fluorine intake has an effect on elevated TSH levels. Hence, it is necessary in many cases to introduce iodine supplementation and target the consumption of mineral or spring water containing no controversial fluorine [48].

On the other hand, it should not be forgotten that an excess of iodine can cause thyroid function disorders, in the form of both hyperthyroidism and hypothyroidism, especially in women with anti-thyroid antibodies. Acute iodine poisoning may lead to gastrointestinal disturbance, cardiac disorders or even coma [45].

The publication made by Zhou and Condo has shown impaired psychomotor development of children at 18 months of age, assessed on the Bayley-III scale, both in case of supplementing too low ( $<220 \mathrm{mcg} /$ day) and too high ( $>391 \mathrm{mcg} /$ day) iodine doses before 20 weeks of gestation [49].

An ideal way to adjust the iodine dose to the needs of the individual pregnant women would be measuring the levels of anti-thyroid antibodies, thyroid hormones and renal iodine clearance, which should increase from $150 \mathrm{mcg} / \mathrm{L}$ up to $249 \mathrm{mcg} / \mathrm{L}$ during pregnancy. Abnormal TSH, fT3 and fT4 serum levels reflect thyroid dysfunction, while elevated thyroglobulin ( $\mathrm{Tg}$ ) level is an indirect indicator of iodine deficiency and iodine concentration in urine (UIC) $>499 \mathrm{mcg} / \mathrm{L}$ indicates its excessive intake [45].

Considering the difficulties in performing the above tests on a regular basis, the average requirement for iodine in pregnant women has been estimated in various regions of the world and the recommended dose of supplementation in pregnancy ranges from $150 \mathrm{mcg} /$ day in Australia and New Zealand, $200 \mathrm{mcg} /$ day in the European Union countries (EFSA) [50] to $220 \mathrm{mcg} /$ day in the USA [2].

The maximum safe dose of iodine in the general population, which does not seem to cause adverse effects in healthy pregnant women, has been accepted to be $600 \mathrm{mcg} /$ day in the EU countries and 1,100 mcg/day in the USA [45]. However, these doses seem too high because of high incidence of thyroid gland diseases in these areas [2].

\section{Summary}

In light of the latest research it is recommended to:

1. Supplement iodine in all pregnant women with no history of thyroid gland disease at a dose of 150-200 mcg per day,

2. Supplement iodine in women with thyroid gland disease while controlling thyroid hormones and the concentration of anti-thyroid antibodies. 


\section{FOLIC ACID}

Folate participates in a number of chemical reactions responsible for transferring carbon units (OCM, one carbon metabolism), which consists of: folate transformations, homocysteine methylation and transsulfuration. These reactions play a key role in the synthesis of nucleic acids, proteins, reactive forms of oxygen and epigenetic regulation [51] (Fig. 2).

Homocysteine is an amino acid synthesized in all body cells from an exogenous amino acid - methionine, derived mostly from animal proteins. In the above homocysteine-methionine pathway, folic acid is involved (Fig. 3). Its deficiency may lead to hyperhomocysteinemia, defined as serum homocysteine concentration $>15 \mathrm{mcmol} / \mathrm{L}$.

The main role of homocysteine is to rebuild damaged tissue, though it should not be forgotten that it also exhibits prothrombic properties.

Hyperhomocysteinemia, which occurs with folate deficiency can carry a number of adverse effects in homeostasis of both pregnant woman and the fetus. An elevated serum homocysteine concentration is considered to be a risk factor for development of many diseases, especially of the cardiovascular system and indirectly of dementia, as a result of atherosclerosis development in the cerebral vessels [51, 52]. It may also have an adverse effect on the course of pregnancy, impairing the blood supply to the placenta, which may lead to fetal growth restriction (FGR) or intrauterine

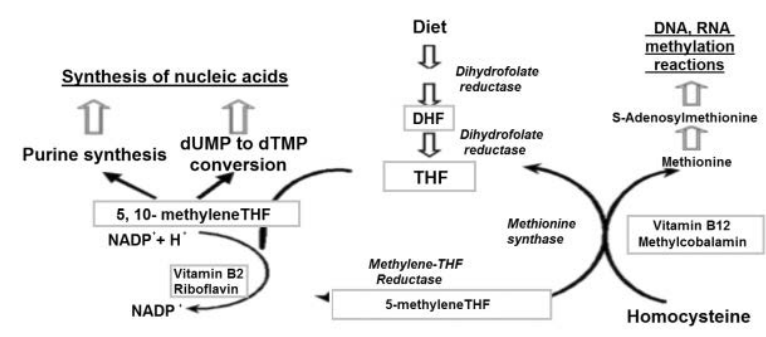

Figure 2. The effect of folic acid on homeostasis [51]

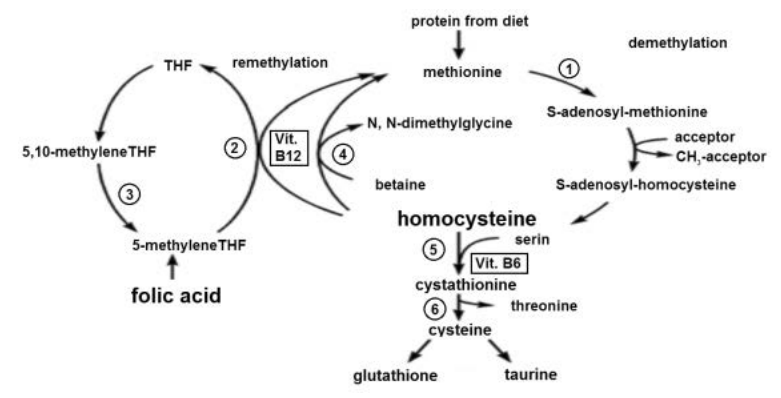

Figure 3. Homocysteine metabolism pathway [51]; 1 - methionine adenosyltransferase; 2 - methionine synthase; 3 - reductase 5 , 10-methylenetetrahydrofolate (MTHFR); 4 - betaine-homocysteine methyltransferase; 5 - cystathionine $\beta$ syntase; $6-\gamma$-cystathionase [53] death, as well as a negative impact on the development of the CNS of the fetus [51]

An excessive consumption of animal proteins causes temporary increase in serum homocysteine levels. However, there is no convincing evidence that an increased methionine intake causes chronic elevation of homocysteine, especially in people with proper B vitamins intake, including folic acid. An unbalanced diet is a common cause of increase in homocysteine concentration, including vegetarian and vegan diets, with no additional, yet in this case, necessary supplementation of folic acid and other vitamins, especially the B complex. Modern food processing can also lead to a breakdown of a significant percentage (30-55\%) of essential vitamins [53]

It is important to remember about other relevant causes of hyperhomocysteinemia, such as liver or kidney failure, diabetes, malignant tumors or using drugs like methotrexate (which inhibits dihydrofolate reductase), metformin (which affects the metabolism of B12 vitamin), cholestyramine (which reduces the absorption of B12 and folate), carbamazepine and valproic acid (which affect the folic acid metabolism), stimulants and genetically determined deficiency or lack of enzymes involved in homocysteine metabolism, especially of the cystathionine $\beta$-synthase (occurring 1/200-400 000 births) [53].

In recent years, possible contribution of another enzyme involved in folic acid metabolism and therefore homocysteine was pointed out - 5, 10-reductase methylenetetrahydrofolate (MTHFR). It is believed, that MTHFR activity can be moderately reduced in cases of commonly occurring polymorphic variants c.665C $>\mathrm{T}$ (known so far as c.677C $>\mathrm{T}$ ) and c.1298A > C in the MTHFR gene (NM_005957). They are particularly common in white and Caucasian race, also in Poland, reaching up to $50 \%$ of general population.

Currently, however, there is no sufficiently documented evidence indicating significant impact of the mentioned variants on the incidence of high homocysteine concentration or neural tube defects [54]. There is no indication to use higher doses of folic acid or its active form in these cases. Considering the inverse correlation between homocysteine and folic acid serum levels it has been established that folic acid concentration $>10 \mathrm{nmol} / \mathrm{L}$ in blood serum and > $349 \mathrm{nmol} / \mathrm{L}$ in erythrocytes reflects its sufficient consumption in a healthy adult population. Based on randomized studies it has been established that daily requirement for folates, in this group, allowing for maintenance of the proper concentration in blood is $400 \mathrm{mcg}$, including $250 \mathrm{mcg}$ for natural folates and $150 \mathrm{mcg}$ for folic acid, respectively. To achieve the same level of folate in erythrocytes, pregnant women require an intake of about 600 mcg in the II and III trimesters, and about 500 mcg daily during lactation [50]. 
Folate deficiency can also result in impaired DNA synthesis and cell division, especially in rapidly growing tissues like bone marrow or fetal tissues. As a result of folic acid deficiency erythrocytes may form an abnormal nucleus, megaloblastic anemia as well as miscarriages and birth defects may develop, especially neural tube defects, which incidence is globally estimated at about $18.6 / 10,000$ births [55].

Although the etiology of neural tube defects is multifactorial and both genetic and environmental factors take part in their formation, it is now known that one carbon metabolism plays a significant role in the process of neural tube closure. Mutations in genes coding enzymes participating in the OCM pathways are most certainly associated with the risk of natural tube defects (NTD) incidence.

However, despite of 30 years of research on genes involved in the process of neural tube closure, no simple correlation between mutations in specific genes and the incidence of NTD was found. Research carried out in the recent years indicate that the underlying cause of neural tube defects is polygenic and the risk of their occurrence increases with the accumulation of various mutations [55].

Neural tube closure occurs within 28 days after conception. Abnormalities in the course of this process result in formation of defects, such as anencephaly or spina bifida.

In $90 \%$ of cases, spina bifida is accompanied by type II Arnold-Chiari malformation, which involves displacement of the hindbrain structures to the spinal canal.

The correlation between folate deficiency and the incidence of NTD was discovered in 1965. CDC followed by issuing a recommendation in 1991 that women with prior NTD child should supplement $4 \mathrm{mg}$ of folic acid per day for a strictly defined time, i.e. at least 4 weeks before the pregnancy and during its first 12 weeks. The recommendation was based on a research conducted on a group of 1,195 women with a history of NTD, in which the incidence of NTD in the next pregnancy was compared in a group of women using $4 \mathrm{mg}$ of folic acid and in a folate-free group, finding a reduction of the NTD risk from $3.5 \%$ to $1 \%$ with no adverse effects [56].

Prolonged use of $4 \mathrm{mg} / \mathrm{d}$ of folic acid may have potentially harmful effects on the fetus. A research by Johns Hopkins Bloomberg School of Public Health has shown that supplementing high doses of folates in pregnancy may increase the risk of autism in children. Due to the above report, in 2016 RCOG recommended using higher than $400 \mathrm{mcg} / \mathrm{d}$ doses of folic acid only in strictly defined groups of pregnant women and not longer than until 12 weeks of gestation [57].

In 2008, a study consisting of 700 women in India, Yajka and Deshpande showed possible effect of high folic acid concentration in erythrocytes of women at 28 weeks of gestation on the risk of developing insulin resistance in their offspring, measured by the HOMA-R index in 6-year-old children.
Excess of folic acid can also mask first symptoms of vitamin B12 deficiency-megaloblastic anemia $[59,60]$. There have also been studies showing that using lower doses of folic acid for a longer period of time is effective in prophylaxis of neural tube defects [61-65].

However, selection of population groups in the above research does not authorize a change in the currently advocated use of $4 \mathrm{mg}$ of folic acid in a group of patients with a history of NTD at least 4 weeks before planned conception and first 12 weeks of pregnancy.

Is should be remembered that although maternal folate deficiency may cause neural tube defects in the fetus, most NTDs occur in children whose mothers had normal levels of folic acid in blood serum. Exogenous folic acid prevents some neural tube defects most probably by epigenetic regulation (methylation) and regulation of cell division (purine synthesis).

Relevant environmental risk factors for NTD include: pregestational diabetes (risk 2-10 times higher), $\mathrm{BMI}>30$ (risk 1.4-3.5 higher), use of antiepileptic drugs (carbamazepine and valproic acid are associated with 1-2\% of NTD risk), genetic conditions- neural tube defects in previous pregnancy or in a family history [66-70].

Serum folate level increases right after consumption and the effect lasts briefly, while the level in erythrocytes reflects the stored amount in the body better.

It has been shown that at RBC folate concentration of $1,000-1,300 \mathrm{nmol} / \mathrm{L}$ the risk of NTD is 7.9/10,000 pregnancies. Further increase of folate concentration in erythrocytes did not significantly reduce the risk [66] (Fig. 4).

In 1998, the FDA recommended fortifying foods with folic acid. Adding a dose of $0.4 \mathrm{mg}$ of folate per $100 \mathrm{~g}$ to basic products (bread, pasta, flour) allowed an increase in the daily intake from $0.288 \pm 195 \mathrm{mg}$ to $0.550 \pm 279 \mathrm{mg}$, which resulted in a decline of NTD incidence from 6.86 to $4.04 / 10,000$ pregnancies. The above food enrichment was also introduced by countries like Canada, South Africa Chile, Saudi Arabia with a similar result.

In the EUROCAT study including 34 studies from 8 European countries where no food fortification was introduced and only supplementation of folic acid in preconception and early pregnancy was used between 1980 and 2001, such relevant reduction of NTD incidence was not obtained. The incidence of neural tube defects in those countries was $9.1 / 10,000$ pregnancies. Furthermore, the research has indicated that folate supplementation in the preconception period does not exceed $50 \%$. Though one should keep in mind that about $60 \%$ of all pregnancies is unplanned!

A 2017 in Germany study in a population of healthy, non-pregnant women, excluding women with diabetes, $\mathrm{BMI}>30$ or with chronic gastrointestinal diseases resulting in malabsorption such as colitis ulcerosa, Crohn's or 


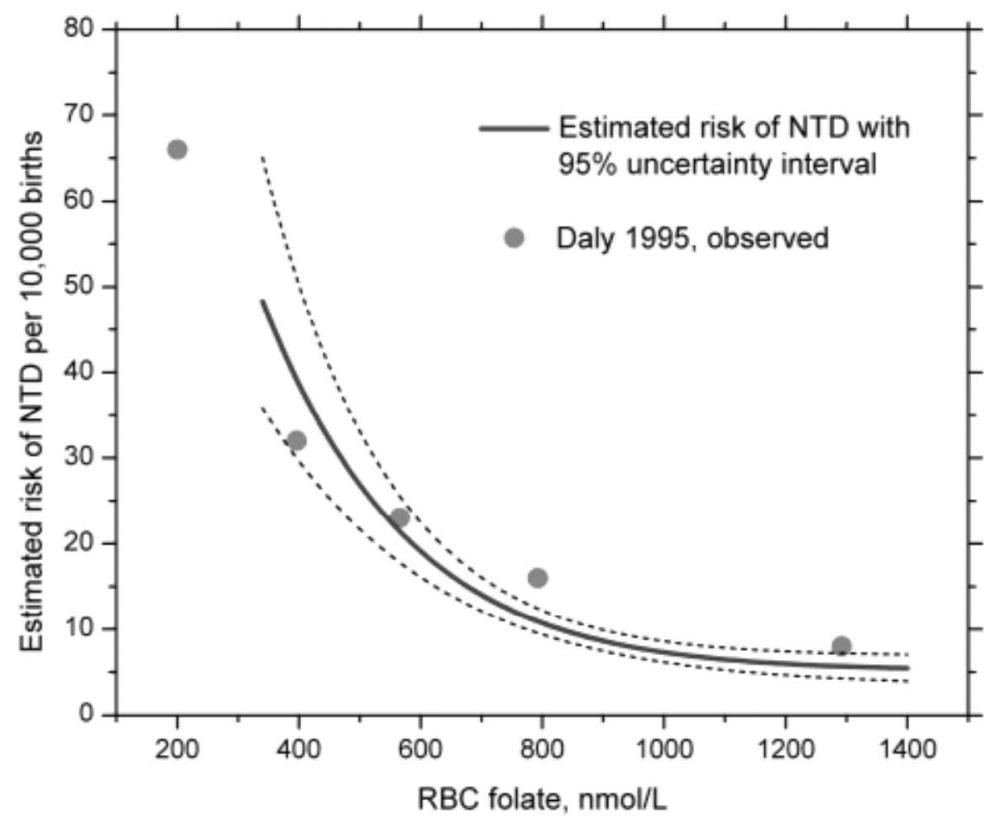

Figure 4. Red blood cell dependent risk of natural tube defects

celiac disease, has shown that $88 \%$ of them have folate concentration in $\mathrm{RBC}<906 \mathrm{nmol} / \mathrm{l}, 6 \%<340 \mathrm{nmol} / \mathrm{L}$, and the mean folate concentration was $640 \mathrm{nmol} / \mathrm{L}$. Folic acid supplementation in a dose of $0.8 \mathrm{mg} / \mathrm{d}$ for 4 weeks allow for folate concentration in RBC > $906 \mathrm{nmol} / \mathrm{L}$ in $45 \%$, while supplementation of $0.04 \mathrm{mg} / \mathrm{d}$ in the same period of time allowed for reaching $>906 \mathrm{nmol} / \mathrm{L}$ in only $31 \%$ of respondents. Extending the supplementation period to 8 weeks obtained the required dose in $83 \%$ of the $0.8 \mathrm{mg} / \mathrm{d}$ dose group and in $54 \%$ of the $0.4 \mathrm{mg} / \mathrm{d}$ dose group, respectively.

In a 2019 meta-analysis it has been shown that supplementation of $0.4 \mathrm{mcg} / \mathrm{d}$ of folate for about 36 weeks increases the folate levels in RBC by about 78\% compared to the initial baseline and maintaining this concentration with further supplementation with the same dose, while the higher the increase, the lower the initial concentration.

For example, in case of folate concentration in RBC at $600 \mathrm{nmol} / \mathrm{L}$, a $400 \mathrm{mcg} / \mathrm{d}$ dose causes an increase in folate concentration in RBC to $1,065 \mathrm{nmol} / \mathrm{L}$ within 9 months [72].

In a 2019 recommendation for food producers, the FDA established the optimal daily dose of consumed folate in the form of fortified food for the general population as $0.4 \mathrm{mg} / \mathrm{d}$, $0.8 \mathrm{mg} / \mathrm{d}$ during pregnancy and lactation and the safe upper limit was established to be $1 \mathrm{mg}$ [73].

In 2019 EFSA recommended the daily folate consumption to be $0.33 \mathrm{mg} / \mathrm{d}$ in a population of healthy men and non-pregnant women, $0.6 \mathrm{mg} / \mathrm{d}$ for pregnant women and $0.5 \mathrm{mg} / \mathrm{d}$ for breastfeeding women.

According to current research, the best solution to prevent the neural tube defects seems to be obligatory fortifi- cation of food with folic acid, which also is an appeal of the Polish Society of Gynecologists and Obstetricians.

The CDC and Institute of Medicine recommend that all women of reproductive-age intake at least $0.4 \mathrm{mg} / \mathrm{d}$ of folic acid in form of supplements, fortified food or the combination of both as an addition to a natural, folate-rich diet [56, 74].

\section{Summary}

According to the up-to-date knowledge, it is recommended to:

1. Use $0.4 \mathrm{mg} / \mathrm{d}$ of folic acid in all women of reproductive age, as a supplement to natural, folate-rich diet,

2. Supplement $0.4-0.8 \mathrm{mg} / \mathrm{d}$ of folic acid in the first trimester (before 12 weeks of gestation),

3. Supplement $0.6-0.8 \mathrm{mg} / \mathrm{d}$ of folic acid after 12 weeks of gestation and during lactation in a population of women with no additional risk factors,

4. Supplement $4 \mathrm{mg} / \mathrm{d}$ of folic acid in women with history of NTD in prior pregnancy, in a strictly defined period of time, i.e. at least 4 weeks before planned conception and during the first 12 weeks of pregnancy, then reduction of the dose to the levels of the general population,

5. Use $0.8 \mathrm{mg} / \mathrm{d}$ of folate for at least 3 months before planned conception and during pregnancy and lactation in women with high risk of folate deficiency and NTD:

- with type I or II diabetes before pregnancy,

- use of antiepileptic drugs, methotrexate, cholestyramine, metformin, sulfadiazine before or during pregnancy, 
- using stimulants,

- with liver or kidney failure,

- with BMI > 30,

- after bariatric surgery or with gastrointestinal diseases resulting in malabsorption (Crohn's disease, colitis ulcerosa, celiac disease).

\section{REFERENCES}

1. Siró I, Kápolna E, Kápolna $B$, et al. Functional food. Product development, marketing and consumer acceptance--a review. Appetite. 2008; 51(3): 456-467, doi: 10.1016/j.appet.2008.05.060, indexed in Pubmed: 18582508.

2. Brown B, Wright C. Safety and efficacy of supplements in pregnancy. Nutr Rev. 2020; 78(10): 813-826, doi: 10.1093/nutrit/nuz101, indexed in Pubmed: 31925443.

3. Milman NT. Dietary Iron Intake in Pregnant Women in Europe: A Review of 24 Studies from 14 Countries in the Period 1991-2014. J Nutr Metab. 2020; 2020: 7102190, doi: 10.1155/2020/7102190, indexed in Pubmed: 32185079.

4. World Health Organization. Haemoglobin concentrations for the diagnosis of anaemia and assessment of severity. Geneva, 2011.

5. Sułek K. Problemy hematologiczne w położnictwie i ginekologii. Pytania i odpowiedzi. Medycyna Praktyczna, Kraków 2015.

6. Bręborowicz GH. Położnictwo Tom 2 Medycyna Matczyno-Płodowa. PZWL, Warszawa 2012

7. Centers for Disease Control and Prevention (CDC). Recommendations to prevent and control iron deficiency in the United States. Centers for Disease Control and Prevention. MMWR Recomm Rep. 1998; 47(RR-3): 1-29, indexed in Pubmed: 9563847.

8. World Health Organization. The global prevalence of Anaemia in 2011. Geneva, 2015.

9. RCOG statement: Study claims multivitamin and mineral supplements for pregnant women aren't needed. https://www.rcog.org. uk/en/news/rcog-statement-studyclaims-multivitamin-and-mineral-supplements-for-pregnant-women-arent-needed/ (19.05.2020).

10. Royal Australian and New Zealand College of Obstetricians and Gynaecologists. Vitamin and mineral supplementation and pregnancy. https:// www.hps.com.au/wpcontent/uploads/2019/04/Vitamin-and-mineral-supplementation-in-pregnancy-CObs-25-Review-Nov-2014-Amended-May-2015.pdf (19.05.2020).

11. Hansen JB, Tonnesen MF, Madsen AN, et al. Divalent metal transporter 1 regulates iron-mediated ROS and pancreatic $\beta$ cell fate in response to cytokines. Cell Metab. 2012; 16(4): 449-461, doi: 10.1016/j. cmet.2012.09.001, indexed in Pubmed: 23000401.

12. Hansen JB, Moen IW, Mandrup-Poulsen T. Iron: the hard player in diabetes pathophysiology. Acta Physiol (Oxf). 2014; 210(4): 717-732, doi: 10.1111/apha.12256, indexed in Pubmed: 24521359.

13. Jirakittidul P, Sirichotiyakul S, Ruengorn C, et al. Effect of iron supplementation during early pregnancy on the development of gestational hypertension and pre-eclampsia. Arch Gynecol Obstet. 2018; 298(3): 545-550, doi: 10.1007/s00404-018-4821-6, indexed in Pubmed: 29951711.

14. Maitra S, Mukthapuram A, Huligol G, et al. Increased Serum Ferritin and Iron Levels in Preeclampsia. IOSR. 2019; 5(2): 50-52.

15. Shaji Geetha N, Bobby Z, Dorairajan G, et al. Increased hepcidin levels in preeclampsia: a protective mechanism against iron overload mediated oxidative stress? J Matern Fetal Neonatal Med. 2020 [Epub ahead of print]: 1-6, doi: 10.1080/14767058.2020.1730322, indexed in Pubmed: 32079434.

16. Cheng $Y, L i T, H e ~ M$, et al. The association of elevated serum ferritin concentration in early pregnancy with gestational diabetes mellitus: a prospective observational study. Eur J Clin Nutr. 2020; 74(5): 741-748, doi: 10.1038/s41430-019-0542-6, indexed in Pubmed: 31932742.

17. McElduff A, Rawal S, Hinkle SN, et al. A longitudinal study of iron status during pregnancy and the risk of gestational diabetes: findings from a prospective, multiracial cohort. Diabetologia. 2017; 60(2): 249-257, doi: 10.1007/s00125-016-4149-3, indexed in Pubmed: 27830277.

18. Kataria Y, Wu Y, Horskjær Pd, et al. Iron Status and Gestational Diabetes-A Meta-Analysis. Nutrients. 2018; 10(5), doi: 10.3390/nu10050621, indexed in Pubmed: 29762515.

19. Zhao L, Lian J, Tian J, et al. Dietary intake of heme iron and body iron status are associated with the risk of gestational diabetes mellitus: a systematic review and metaanalysis. Asia Pac J Clin Nutr. 2017; 26(6): 1092-1106.

20. Zhang C, Rawal S. Dietary iron intake, iron status, and gestational diabetes. Am J Clin Nutr. 2017; 106(Suppl 6): 1672S-1680S, doi: 10.3945/ajcn.117.156034, indexed in Pubmed: 29070554.

21. Helin A, Kinnunen TI, Raitanen J, et al. Iron intake, haemoglobin and risk of gestational diabetes: a prospective cohort study. BMJ Open. 2012;2(5), doi: 10.1136/bmjopen-2012-001730, indexed in Pubmed: 23015603.

22. Karowicz-Bilińska A, Nowak-Markwitz E. Rekomendacje Polskiego Towarzystwa Ginekologicznego w zakresie stosowania witamin i mikroelementów u kobiet planujących ciążę, ciężarnych i karmiących. Ginekol Pol. 2014; 85(5): 395-399.

23. Parchem K, Bartoszek A. Fosfolipidy oraz produkty ich hydrolizy jako żywieniowe czynniki prewencyjne w chorobach cywilizacyjnych. Postepy Hig Med Dosw. 2016; 70: 1343-1361.

24. Cole GM, Ma QL, Frautschy SA. Omega-3 fatty acids and dementia. Prostaglandins Leukot Essent Fatty Acids. 2009; 81(2-3): 213-221, doi: 10.1016/j.plefa.2009.05.015, indexed in Pubmed: 19523795.

25. Bakouei F, Delavar MA, Mashayekh-Amiri S, et al. Efficacy of $n-3$ fatty acids supplementation on the prevention of pregnancy induced-hypertension or preeclampsia: A systematic review and meta-analysis. Taiwan J Obstet Gynecol. 2020; 59(1): 8-15, doi: 10.1016/j.tjog.2019.11.002, indexed in Pubmed: 32039806.

26. Kar $S$, Wong $M$, Rogozinska $E$, et al. Effects of omega-3 fatty acids in prevention of early preterm delivery: a systematic review and meta-analysis of randomized studies. Eur J Obstet Gynecol Reprod Biol. 2016; 198: 40-46, doi: 10.1016/j.ejogrb.2015.11.033, indexed in Pubmed: 26773247.

27. Simmonds LA, Sullivan TR, Skubisz M, et al. Docosahexaenoic Acid and Preterm Birth. Ann Nutr Metab. 2016; 69 Suppl 1(9): 29-34, doi: 10.1159/000448263, indexed in Pubmed: 27842314.

28. Middleton P, Gomersall JC, Gould JF, et al. Omega-3 fatty acid addition during pregnancy. Cochrane Database Syst Rev. 2018; 11: CD003402, doi: 10.1002/14651858.CD003402.pub3, indexed in Pubmed: 30480773.

29. Olsen SF, Halldorsson TI, Thorne-Lyman AL, et al. Plasma Concentrations of Long Chain N-3 Fatty Acids in Early and Mid-Pregnancy and Risk of Early Preterm Birth. EBioMedicine. 2018; 35: 325-333, doi: 10.1016/j. ebiom.2018.07.009.

30. Jackson KH, Harris WS. A Prenatal DHA Test to Help Identify Women at Increased Risk for Early Preterm Birth: A Proposal. Nutrients. 2018; 10(12), doi: 10.3390/nu10121933, indexed in Pubmed: 30563193.

31. de Se, Beck KL, Conlon CA. Nutrition in pregnancy. OGRM 2019.

32. Makrides M, Gibson RA, McPhee AJ, et al. DOMlnO Investigative Team. Effect of DHA supplementation during pregnancy on maternal depression and neurodevelopment of young children: a randomized controlled trial. JAMA. 2010; 304(15): 1675-1683, doi: 10.1001/jama.2010.1507, indexed in Pubmed: 20959577.

33. Makrides $M$, Best $K$, Yelland L, et al. A Randomized Trial of Prenatal n-3 Fatty Acid Supplementation and Preterm Delivery. N Engl J Med. 2019; 381(11): 1035-1045, doi: 10.1056/NEJMoa1816832, indexed in Pubmed: 31509674.

34. Carlson SE, Gajewski BJ, Valentine CJ, et al. Assessment of DHA on reducing early preterm birth: the ADORE randomized controlled trial protocol. BMC Pregnancy Childbirth. 2017; 17(1): 62, doi: 10.1186/s12884-0171244-5, indexed in Pubmed: 28193189.

35. Lips P. Vitamin D physiology. Prog Biophys Mol Biol. 2006; 92(1): 4-8, doi: 10.1016/j.pbiomolbio.2006.02.016, indexed in Pubmed: 16563471.

36. Thacher TD, Fischer PR, Obadofin MO, et al. Comparison of metabolism of vitamins D2 and D3 in children with nutritional rickets. J Bone Miner Res. 2010; 25(9): 1988-1995, doi: 10.1002/jbmr.99, indexed in Pubmed: 20499377.

37. Hollis BW.Vitamin D status during pregnancy: The importance of getting it right. EBioMedicine. 2019; 39: 23-24, doi: 10.1016/j.ebiom.2018.12.021, indexed in Pubmed: 30563759.

38. Ganguly A, Tamblyn JA, Finn-Sell S, et al. Vitamin D, the placenta and early pregnancy: effects on trophoblast function. J Endocrinol. 2018; 236(2): R93-R9R103, doi: 10.1530/JOE-17-0491, indexed in Pubmed: 29109081.

39. Palacios C, Kostiuk LK, Peña-Rosas JP. Vitamin D supplementation for women during pregnancy. Cochrane Database Syst Rev. 2019; 7: CD008873, doi: 10.1002/14651858.CD008873.pub4, indexed in Pubmed: 31348529.

40. Chen $Y, Z$ hu $B, W u$ X, et al. Association between maternal vitamin $D$ deficiency and small for gestational age: evidence from a meta-analysis of prospective cohort studies. BMJ Open. 2017; 7(8): e016404, doi: 10.1136/bmjopen-2017-016404, indexed in Pubmed: 28844987. 
41. Milman N, Paszkowski T, Cetin I, et al. Supplementation during pregnancy: beliefs and science. Gynecol Endocrinol. 2016; 32(7): 509-516, doi: 10.3109/09513590.2016.1149161, indexed in Pubmed: 26956254.

42. American Association for Clinical Chemistry. „Vitamin D Tests”. Lab Tests Online (USA). https://labtestsonline.org/tests/vitamin-d-tests (18.07.2020).

43. Rusińska A, Płudowski P, Walczak M, et al. Vitamin D Supplementation Guidelines for General Population and Groups at Risk of Vitamin D Deficiency in Poland-Recommendations of the Polish Society of Pediatric Endocrinology and Diabetes and the Expert Panel With Participation of National Specialist Consultants and Representatives of Scientific Societies-2018 Update. Front Endocrinol (Lausanne). 2018; 9: 246, doi: 10.3389/fendo.2018.00246, indexed in Pubmed: 29904370.

44. Wender-Ożegowska E, Bomba-Opoń D, Brązert J, et al. Standardy Polskiego Towarzystwa Ginekologów i Położników postępowania u kobiet z cukrzyca. Ginekologia i Perinatologia Praktyczna. 2017; 2(5): 215-29.

45. Harding KB, Peña-Rosas JP, Webster AC, et al. lodine supplementation for women during the preconception, pregnancy and postpartum period. Cochrane Database Syst Rev. 2017; 3: CD011761, doi: 10.1002/14651858. CD011761.pub2, indexed in Pubmed: 28260263.

46. Dineva M, Fishpool H, Rayman MP, et al. Systematic review and meta-analysis of the effects of iodine supplementation on thyroid function and child neurodevelopment in mildly-to-moderately iodine-deficient pregnant women. Am J Clin Nutr. 2020; 112(2): 389-412, doi: 10.1093/ajcn/nqaa071, indexed in Pubmed: 32320029.

47. Zimmermann MB, Gizak M, Abbott $K$, et al. lodine deficiency in pregnant women in Europe. Lancet Diabetes Endocrinol. 2015; 3(9): 672-674, doi: 10.1016/S2213-8587(15)00263-6, indexed in Pubmed: 26268907.

48. Kheradpisheh Z, Mirzaei M, Mahvi AH, et al. Impact of Drinking Water Fluoride on Human Thyroid Hormones: A Case-Control Study. Sci Rep. 2018;8(1): 2674, doi: 10.1038/s41598-018-20696-4, indexed in Pubmed: 29422493.

49. Zhou SJ, Condo D, Ryan P, et al. Association Between Maternal lodine Intake in Pregnancy and Childhood Neurodevelopment at Age 18 Months. Am J Epidemiol. 2019; 188(2):332-338, doi: 10.1093/aje/kwy225, indexed in Pubmed: 30452542.

50. Dietary Reference Values for nutrients Summary report. EFSA Supporting Publications. 2017; 14(12), doi: 10.2903/sp.efsa.2017.e15121.

51. Czeczot H. Kwas foliowy w fizjologii i patologii [Folic acid in physiology and pathology. Postepy Hig Med Dosw. 2008; 62: 405-419.

52. Farkas M, Keskitalo S, Smith DEC, et al. Hyperhomocysteinemia in Alzheimer's disease: the hen and the egg? J Alzheimers Dis. 2013; 33(4): 10971104, doi: 10.3233/JAD-2012-121378, indexed in Pubmed: 23099812.

53. Gasiorowska D, Korzeniowska K, Jabłecka A. Homocysteina. Farmacja Wspolcz. 2008; 1: 169-175.

54. Moczulska H, Pesz K, Gach A, et al. Stanowisko ekspertów Polskiego Towarzystwa Genetyki Człowieka i Polskiego Towarzystwa Ginekologów i Położników w sprawie zlecania i interpretacji wyników badań pod kątem wariantów genetycznych w genie MTHFR. Ginekologia i Perinatologia Praktyczna. 2017; 5: 234-238.

55. Steele JW, Kim SE, Finnell RH. One-carbon metabolism and folate transporter genes: Do they factor prominently in the genetic etiology of neural tube defects? Biochimie. 2020; 173: 27-32, doi: 10.1016/j. biochi.2020.02.005, indexed in Pubmed: 32061804

56. Arth A, Tinker S, Moore C, et al. Centers for Disease Control and Prevention, Centers for Disease Control and Prevention (CDC), Centers for Disease Control and Prevention (CDC), Centers for Disease Control and Prevention (CDC), Centers for Disease Control and Prevention (CDC), Centers for Disease Control and Prevention (CDC), Centers for Disease Control (CDC). Use of folic acid for prevention of spina bifida and other neural tube defects--1983-1991. MMWR Morb Mortal Wkly Rep. 1991; 40(30): 513-516, indexed in Pubmed: 2072886.

57. RCOG statement: Study claims too much folate can increase autism risk. https://www.rcog.org.uk/en/news/rcog-statement-study-claims-too-m uch-folate-canincrease-autism-risk/ (23.07.2020)
58. Yajnik CS, Deshpande SS, Jackson AA, et al. Vitamin B12 and folate concentrations during pregnancy and insulin resistance in the offspring: the Pune Maternal Nutrition Study. Diabetologia. 2008; 51(1): 29-38, doi: 10.1007/s00125-007-0793-y, indexed in Pubmed: 17851649.

59. Paul L, Selhub J. Interaction between excess folate and low vitamin B12 status. Mol Aspects Med. 2017; 53: 43-47, doi: 10.1016/j. mam.2016.11.004, indexed in Pubmed: 27876554.

60. Bomba-Opoń D, Hirnle L, Kalinka J, et al. Suplementacja folianów w okresie przedkoncepcyjnym, w ciąży i połogu. Rekomendacje Polskiego Towarzystwa Ginekologów i Położników. Ginekologia i Perinatologia Praktyczna. 2017; 2(5): 210-214.

61. Czeizel AE, Dudás I. Prevention of the first occurrence of neural-tube defects by periconceptional vitamin supplementation. N Engl J Med. 1992; 327(26): 1832-1835, doi: 10.1056/NEJM199212243272602, indexed in Pubmed: 1307234.

62. De Wals $\mathrm{P}$, Van Allen MI, Lowry RB, et al. Reduction in neural-tube defects after folic acid fortification in Canada. N Engl J Med. 2007; 357(2): 135-142, doi: 10.1056/NEJMoa067103, indexed in Pubmed: 17625125.

63. Correction: Prevention of Neural-Tube Defects with Folic Acid in China. N Engl J Med. 1999; 341 (24): 1864, doi: 10.1056/NEJM199912093412424, indexed in Pubmed: 10588975.

64. Milunsky A, Jick H, Jick SS, et al. Multivitamin/folic acid supplementation in early pregnancy reduces the prevalence of neural tube defects. JAMA. 1989; 262(20): 2847-2852, doi: 10.1001/jama.262.20.2847, indexed in Pubmed: 2478730.

65. Castillo-Lancellotti C, Tur JA, Uauy R. Impact of folic acid fortification of flour on neural tube defects: a systematic review. Public Health Nutr. 2013; 16(5): 901-911, doi: 10.1017/S1368980012003576, indexed in Pubmed: 22850218.

66. van Gool JD, Hirche $\mathrm{H}$, Lax $\mathrm{H}$, et al. Folic acid and primary prevention of neural tube defects: A review. Reprod Toxicol. 2018; 80: 73-84, doi: 10.1016/j.reprotox.2018.05.004, indexed in Pubmed: 29777755.

67. Parker SE, Yazdy MM, Tinker SC, et al. The impact of folic acid intake on the association among diabetes mellitus, obesity, and spina bifida. Am J Obstet Gynecol. 2013; 209(3): 239.e1-239.e8, doi: 10.1016/j. ajog.2013.05.047, indexed in Pubmed: 23711668.

68. Shankar P, Boylan M, Sriram K. Micronutrient deficiencies after bariatric surgery. Nutrition. 2010; 26(11-12): 1031-1037, doi: 10.1016/j. nut.2009.12.003, indexed in Pubmed: 20363593.

69. Wang M, Wang ZP, Gao LJ, et al. Maternal body mass index and the association between folic acid supplements and neural tube defects. Acta Paediatr. 2013; 102(9): 908-913, doi: 10.1111/apa.12313, indexed in Pubmed: 23750819.

70. Jędrzejczak J, Bomba-Opoń D, Jakiel G, et al. Managing epilepsy in women of childbearing age - Polish Society of Epileptology and Polish Gynecological Society Guidelines. Ginekol Pol. 2017; 88(5): 278-284, doi: 10.5603/GP.a2017.0053, indexed in Pubmed: 28580576.

71. Obeid R, Schön C, Wilhelm M, et al. The effectiveness of daily supplementation with 400 or $800 \mu \mathrm{g} /$ day folate in reaching protective red blood folate concentrations in nonpregnant women: a randomized trial. Eur J Nutr. 2018; 57(5): 1771-1780.

72. Crider KS, Devine O, Qi YP, et al. Systematic Review and Bayesian Meta-analysis of the Dose-response Relationship between Folic Acid Intake and Changes in Blood Folate Concentrations. Nutrients. 2019; 11(1), doi: 10.3390/nu11010071, indexed in Pubmed: 30609688.

73. Code of Federal Regulations Title 21, Sec. 101.79 Health claims: Folate and neural tube defects. https://www.accessdata.fda.gov/scripts/cdrh/cfdocs/cfcfr/CFRSearch.cfm?fr=101.79 (19.05.2020).

74. Institute of Medicine (US) Standing Committee on the Scientific Evaluation of Dietary Reference Intakes and its Panel on Folate, Other B Vitamins, and Choline. Dietary Reference Intakes for Thiamin, Riboflavin, Niacin, Vitamin B6, Folate, Vitamin B12, Pantothenic Acid, Biotin, and Choline. National Academies Press, Washington 1998. 